\title{
New Iridoid Glucosides from the Aerial Parts of Verbena brasiliensis
}

\author{
Masateru Ono, ${ }^{*, a}$ Kanna Oishi, ${ }^{a}$ Hiroaki Abe,${ }^{a}$ Chikako Masuoka, ${ }^{a}$ Masafumi OKawa, ${ }^{b}$ \\ Tsuyoshi IKedA, ${ }^{c}$ and Toshihiro NOHARA ${ }^{c}$ \\ ${ }^{a}$ Kyushu Tokai University School of Agriculture; 5435 Minamiaso, Aso, Kumamoto 869-1404, Japan: ${ }^{b}$ Faculty of \\ Pharmaceutical Sciences, Fukuoka University; 8-19-1 Nanakuma, Jonan-ku, Fukuoka 814-0180, Japan: and ${ }^{c}$ Faculty of \\ Medical and Pharmaceutical Sciences, Kumamoto University; 5-1 Oe-honmachi, Kumamoto 862-0973, Japan. \\ Received March 9, 2006; accepted June 20, 2006
}

Two new iridoid glucosides, verbenabraside $A$ (1) and verbenabraside B (2), were isolated from the aerial parts of Verbena brasiliensis VELL., along with six known iridoid glucosides, gelsemiol 3-O- $\beta$-D-glucoside (3), verbraside (4), 9-hydroxysemperoside (5), griselinoside (6), aralidioside (7), and $6 \alpha$-hydroxyforsythide dimethyl ester (8), three known phenylethanoid glycosides, 2 -phenylethyl $\boldsymbol{O}$ - $\boldsymbol{\beta}$-D-xylopyranosyl-(1 $\rightarrow 2)$ - $\beta$-D-glucopyranoside (9), acteoside (10), and leucosceptoside A (11), two known lignan glucosides, dihydroxymethyl-bis(3,5-dimethoxy4-hydroxyphenyl) tetrahydrofuran-9 (or $\left.9^{\prime}\right)-O$ - $\beta$-glucopyranoside (12) and (+)-lyoniresinol $3 \alpha-O$ - $\beta$-D-glucopyranoside (13), a known methyl salicylate glucoside, methyl 2- $O$ - $\beta$-D-glucopyranosylbenzoate (14), and two known sterols, $\beta$-sitosterol 3- $O$ - $\beta$-D-glucopyranoside (15) and $\beta$-sitosterol (16). Their chemical structures were determined on the basis of spectroscopic data. Compound 1 exhibited stronger scavenging effect on the stable free radical 1,1-diphenyl-2-picrylhydrazyl than that of $\alpha$-tocopherol.

Key words Verbena brasiliensis; iridoid glucoside; phenylethanoid glycoside; lignan glucoside; sterol; radical-scavenging effect

Verbena brasiliensis Vell. is native to South America and is now grown wild in Japan. The presence of two iridoid glucosides, brasoside and verbraside, in this plant have been reported. ${ }^{1,2)}$ In the course of our studies on Verbenaceae plants and natural antioxidants, we examined the constituents of the $\mathrm{MeOH}$ extract of the aerial parts of $V$. brasiliensis. The present paper describes the isolation and structural elucidation of two new iridoid glucosides $(\mathbf{1}, \mathbf{2})$, along with six known iridoid glucosides (3-8), three known phenylethanoid glycosides (9-11), two known lignan glucosides $(\mathbf{1 2}, \mathbf{1 3})$, a known methyl salicylate glucoside (14), and two known sterols $(\mathbf{1 5}, \mathbf{1 6})$, as well as the radical-scavenging effects of $\mathbf{1}$ and 2.

The $\mathrm{MeOH}$ extract of the aerial parts of $V$. brasiliensis was partitioned between hexane and aqueous $\mathrm{MeOH}$. The aqueous $\mathrm{MeOH}$ layer was successively subjected to Diaion HP20 and silica gel column chromatography as well as HPLC on ODS to afford 15 compounds $(\mathbf{1}-\mathbf{1 5})$. Chromatography of the hexane layer over silica gel and Diaion HP20 furnished 16.

Compounds 3-16 were identified as gelsemiol 3- $O-\beta$-Dglucoside (3), ${ }^{3)}$ verbraside (4), ${ }^{2)}$ 9-hydroxysemperoside (5), ${ }^{3}$ ) griselinoside (6), ${ }^{4)}$ aralidioside (7), ${ }^{4)} 6 \alpha$-hydroxyforsythide dimethyl ester (8), ${ }^{5)}$ 2-phenylethyl $O$ - $\beta$-D-xylopyranosyl$(1 \rightarrow 2)-\beta$-D-glucopyranoside (9), ${ }^{6}$ acteoside $(\mathbf{1 0}),{ }^{7)}$ leucosceptoside A (11), ${ }^{8)}$ dihydroxymethyl-bis(3,5-dimethoxy4-hydroxyphenyl) tetrahydrofuran-9 (or $9^{\prime}$ )- $O$ - $\beta$-glucopyranoside $\left.(12),{ }^{9}\right)(+)$-lyoniresinol $3 \alpha-O-\beta$-D-glucopyranoside (13), ${ }^{10)}$ methyl $2-O-\beta$-D-glucopyranosylbenzoate $(\mathbf{1 4}),{ }^{11)} \beta$ sitosterol 3- $O$ - $\beta$-D-glucopyranoside (15), ${ }^{12)}$ and $\beta$-sitosterol $(\mathbf{1 6}),{ }^{12)}$ respectively, based on their physical and spectral data, although detailed ${ }^{1} \mathrm{H}-\mathrm{NMR}$ spectral data and ${ }^{13} \mathrm{C}-\mathrm{NMR}$ spectral data in $\mathrm{CD}_{3} \mathrm{OD}$ of $\mathbf{3}-\mathbf{8}$ have not been reported in the literature. The structures of compounds $\mathbf{1}-\mathbf{8}$ are shown in Fig. 1.

Compound 1, called verbenabraside A, was obtained as an amorphous powder and exhibited an $[\mathrm{M}+\mathrm{Na}]^{+}$ion peak at $m / z 547$ in the positive FAB-MS and $[\mathrm{M}-\mathrm{H}]^{-}$ion peak at $m / z 523$ in the negative FAB-MS. The molecular formula of 1 was determined to be $\mathrm{C}_{25} \mathrm{H}_{32} \mathrm{O}_{12}$ using high-resolution (HR) negative FAB-MS. The ${ }^{1} \mathrm{H}-$ and ${ }^{13} \mathrm{C}-\mathrm{NMR}$ signals of 1 were similar to those of $\mathbf{3}$, with additional signals due to one trans-caffeoyl group. These ${ }^{1} \mathrm{H}$ - and ${ }^{13} \mathrm{C}-\mathrm{NMR}$ signals (Tables 1, 2, respectively) were assigned with the aid of ${ }^{1} \mathrm{H}-{ }^{1} \mathrm{H}$ correlation spectroscopy (COSY), heteronuclear multiple-quantum coherence (HMQC), and heteronuclear multiple-bond correlation (HMBC) spectra, and the data of the aglycone moiety of $\mathbf{1}$ were superimposable on those of $\mathbf{3}$. Acidic hydrolysis of $\mathbf{1}$ afforded D-glucose which was confirmed by optical rotation using chiral detection in HPLC analysis, and the coupling constant of the anomeric proton signal $[\delta 4.36(\mathrm{~d}, J=7.5 \mathrm{~Hz})]$ indicated the mode of glycosidic linkage of the glucosyl group to be $\beta$. Furthermore, the signal due to $\mathrm{H}-4$ of the glucosyl group was subjected to acylation shift by $c a$. $1.49 \mathrm{ppm}$ in comparison with that of $\mathbf{3}$ in the ${ }^{1} \mathrm{H}-\mathrm{NMR}$ spectrum, and a key correlation was observed between $\mathrm{H}-4$ of the glucosyl group and the carboxyl carbon of the caffeoyl group in the HMBC spectrum. Based on these data, 1 was defined as gelsemiol 3-O-(4'-trans-caffeoyl)- $\beta$-D-

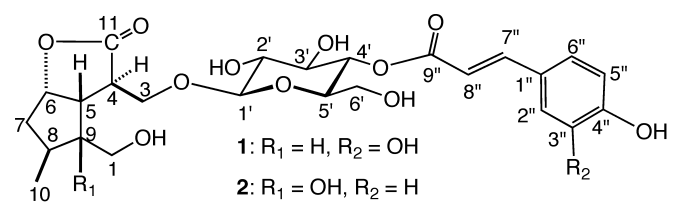

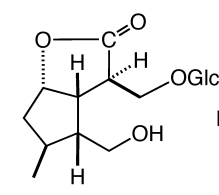
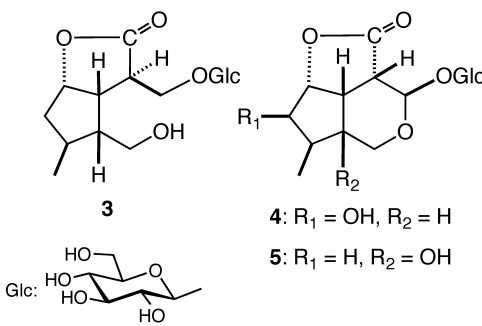

4: $\mathrm{R}_{1}=\mathrm{OH}, \mathrm{R}_{2}=\mathrm{H}$

5: $\mathrm{R}_{1}=\mathrm{H}, \mathrm{R}_{2}=\mathrm{OH}$

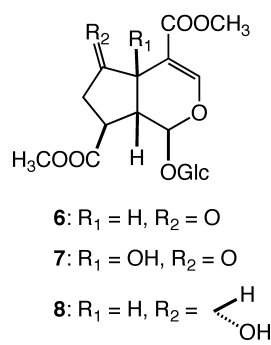

Fig. 1. Structures of $\mathbf{1}-\mathbf{8}$ 


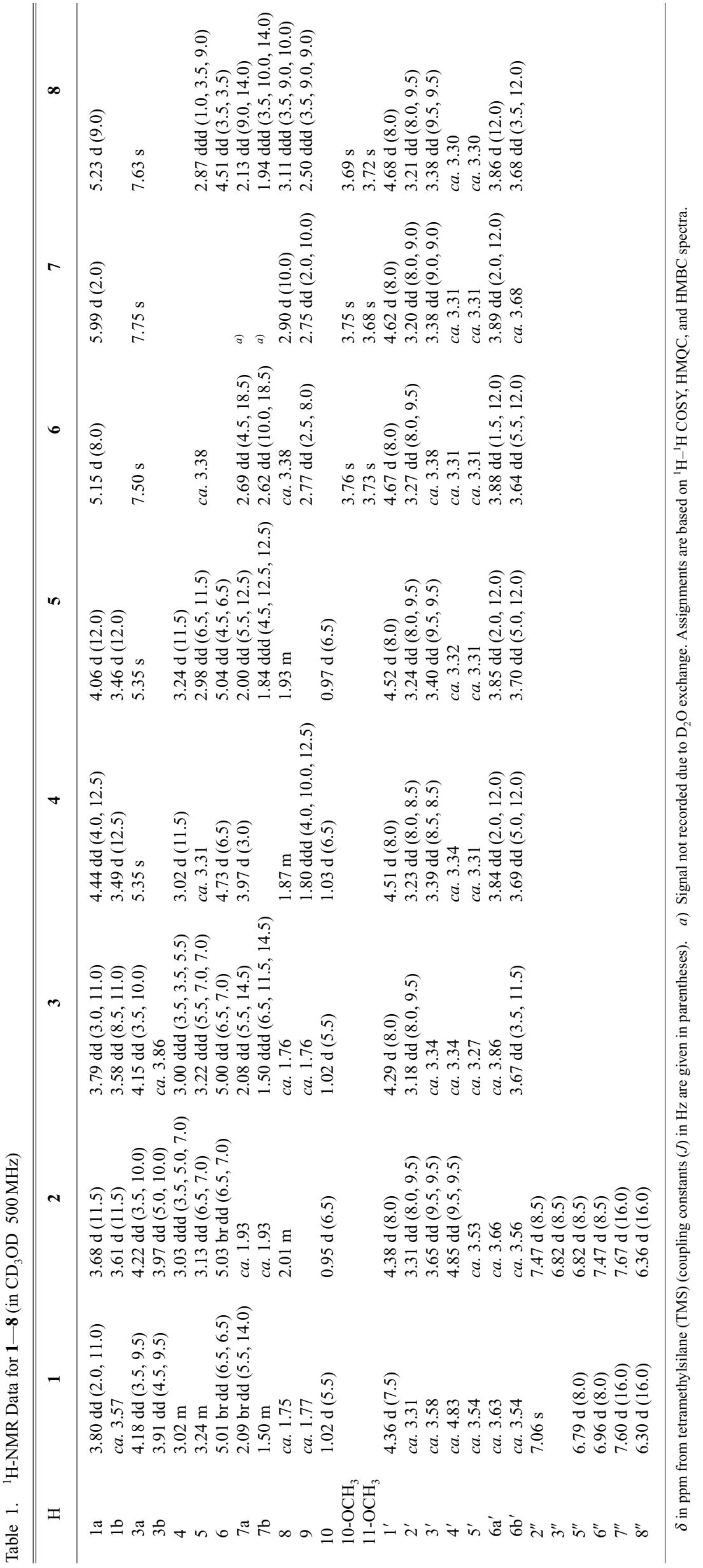


Table 2. ${ }^{13} \mathrm{C}-\mathrm{NMR}$ Data for $\mathbf{1}-\mathbf{8}$ (in $\left.\mathrm{CD}_{3} \mathrm{OD}, 125 \mathrm{MHz}\right)$

\begin{tabular}{|c|c|c|c|c|c|c|c|c|}
\hline $\mathrm{C}$ & 1 & 2 & 3 & 4 & 5 & 6 & 7 & 8 \\
\hline 1 & 61.5 & 65.3 & 61.4 & 57.5 & 61.2 & 97.3 & 95.5 & 100.4 \\
\hline 3 & 70.8 & 70.3 & 70.6 & 98.6 & 98.5 & 154.1 & 156.8 & 155.8 \\
\hline 4 & 43.7 & 44.9 & 43.7 & 42.0 & 44.8 & 105.1 & 106.9 & 106.7 \\
\hline 5 & 46.1 & 54.2 & 46.0 & 35.6 & 48.0 & 40.2 & 74.3 & 44.2 \\
\hline 6 & 85.4 & 84.6 & 85.3 & 88.3 & 84.7 & 213.3 & 209.5 & 74.4 \\
\hline 7 & 42.8 & 39.8 & 42.8 & 77.8 & 39.3 & 37.8 & a) & 39.1 \\
\hline 8 & 34.1 & 37.3 & 34.0 & $38.1^{b)}$ & 37.3 & 40.1 & 36.9 & 45.6 \\
\hline 9 & 52.6 & 84.3 & 52.5 & $38.6^{b)}$ & 74.4 & 41.3 & 48.5 & 43.1 \\
\hline 10 & 17.7 & 11.9 & 17.7 & 11.0 & 10.4 & 175.7 & 174.5 & 177.8 \\
\hline 11 & 180.9 & 180.5 & 180.9 & 177.7 & 177.2 & 168.5 & 167.1 & 169.4 \\
\hline $10-\mathrm{OCH}_{3}$ & & & & & & 53.0 & 53.1 & 52.6 \\
\hline $11-\mathrm{OCH}_{3}$ & & & & & & 52.0 & 51.9 & 51.8 \\
\hline $1^{\prime}$ & 104.6 & 104.5 & 104.5 & 103.9 & 104.0 & 101.1 & 100.8 & 100.8 \\
\hline $2^{\prime}$ & 75.2 & 75.2 & 75.0 & 75.3 & 75.3 & 74.6 & 74.3 & 74.8 \\
\hline $3^{\prime}$ & 75.8 & 75.8 & 78.0 & 78.0 & 78.0 & 78.0 & 77.6 & 77.9 \\
\hline $4^{\prime}$ & 72.6 & 72.6 & 71.7 & 71.4 & 71.4 & 71.6 & 71.5 & 71.6 \\
\hline $5^{\prime}$ & 76.3 & 76.3 & 78.1 & 78.3 & 78.3 & 78.4 & 78.4 & 78.4 \\
\hline $6^{\prime}$ & 62.6 & 62.5 & 62.8 & 62.6 & 62.7 & 62.7 & 62.6 & 62.9 \\
\hline $1^{\prime \prime}$ & 127.8 & 127.2 & & & & & & \\
\hline $2^{\prime \prime}$ & 115.4 & 131.3 & & & & & & \\
\hline $3^{\prime \prime}$ & 146.9 & 117.0 & & & & & & \\
\hline $4^{\prime \prime}$ & 149.8 & 161.4 & & & & & & \\
\hline $5^{\prime \prime}$ & 116.7 & 117.0 & & & & & & \\
\hline $6^{\prime \prime}$ & 123.1 & 131.3 & & & & & & \\
\hline $7^{\prime \prime}$ & 147.7 & 147.3 & & & & & & \\
\hline $8^{\prime \prime}$ & 114.9 & 114.9 & & & & & & \\
\hline $9^{\prime \prime}$ & 168.7 & 168.6 & & & & & & \\
\hline
\end{tabular}

$\delta$ in ppm from TMS. a) Signal not recorded due to $\mathrm{D}_{2} \mathrm{O}$ exchange. b) Assignments may be interchangeable. Assignments are based on ${ }^{1} \mathrm{H}-{ }^{1} \mathrm{H} C O S Y, \mathrm{HMQC}$, and $\mathrm{HMBC}$ spectra.

glucopyranoside.

Compound 2, called verbenabraside $\mathrm{B}$, was obtained as an amorphous powder. The HR negative FAB-MS of $\mathbf{2}$ indicated the same molecular formula as that of 1 . The ${ }^{1} \mathrm{H}$ - and ${ }^{13} \mathrm{C}$ NMR signals of $\mathbf{2}$ were similar to those of $\mathbf{1}$, apart from the appearance of signals due to a 4-substituted phenyl group and one oxygenated quaternary carbon, and the lack of signals due to a 3,4-disubstituted phenyl group and one methine group. In the same manner as for $\mathbf{1}$, these ${ }^{1} \mathrm{H}$ - and ${ }^{13} \mathrm{C}$-NMR signals were examined in detail, and the ${ }^{13} \mathrm{C}$-NMR data of the aglycone moiety of 2 were very similar to those of $9 \alpha$ hydroxygelsemiol, ${ }^{13)}$ except for the signals due to C-3 and C4 , which were considered to be subjected to glycosylation shift, ${ }^{14,15)}$ while the data on the sugar moiety were almost the same as those of 1. In the HMBC spectrum, a key cross-peak was observed between $\mathrm{C}-3$ of the aglycone moiety and anomeric proton. The relative stereochemistry in the aglycone moiety was examined from its nuclear Overhauser and exchange spectroscopy (NOESY) spectrum, and key NOEs were observed, as illustrated in Fig. 2. Consequently, the structure of 2 was concluded to be $9 \alpha$-hydroxygelsemiol 3$O$-( $4^{\prime}$-trans- $p$-coumaroyl)- $\beta$-D-glucopyranoside.

The scavenging effects of $\mathbf{1}$ and $\mathbf{2}$ on the stable free radical 1,1-diphenyl-2-picrylhydrazyl (DPPH) were examined, and the activity was compared with that of the standard antioxidants $\alpha$-tocopherol and L-cysteine, each at a $0.02 \mathrm{~mm}$ concentration. Compound 1 exhibited more potent activity than that of $\alpha$-tocopherol; on the other hand, the activity of $\mathbf{2}$ was weaker than that of L-cysteine. Therefore the catechyl group of 1 was considered to be important for the activity.

As far as we know, $\mathbf{1}$ and $\mathbf{2}$ are new iridoid glucosides, and 3 and 5-16 are the first examples of isolation from the aer-

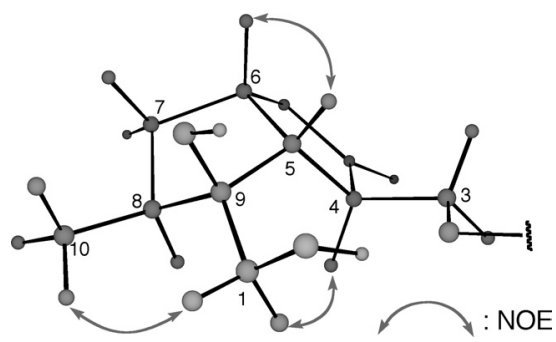

Fig. 2. Selected NOE Correlations Observed in NOESY Spectrum of 2 (in $\left.\mathrm{CD}_{3} \mathrm{OD}, 500 \mathrm{MHz}\right)$

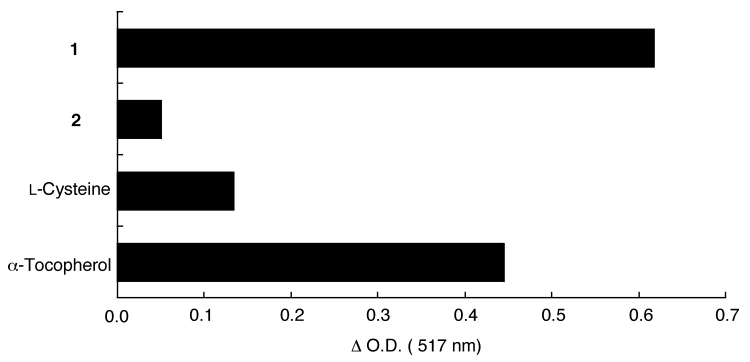

Fig. 3. DPPH Radical-Scavenging Effects of 1, 2, L-Cysteine, and $\alpha$ Tocopherol

The final concentration of each sample tested was $0.02 \mathrm{~mm}$. $\Delta$ O.D., O.D. of control at $517 \mathrm{~nm}(1.1135)$ - O.D. of sample. DPPH, $0.1 \mathrm{~mm}$.

\section{ial parts of Verbena brasiliensis.}

\section{Experimental}

All the instruments and the materials used were the same as cited in the previous report ${ }^{16)}$ unless otherwise specified.

Plant Material The aerial parts of $V$. brasiliensis were collected in Kumamoto prefecture, Japan, in August 2001, and identified by Professor 
Toshihiro Nohara, Faculty of Medical and Pharmaceutical Sciences, Kumamoto University.

Extraction and Isolation The cut fresh aerial parts of $V$. brasiliensis $(3704 \mathrm{~g})$ were extracted with $\mathrm{MeOH}(3900 \mathrm{ml})$ for $5 \mathrm{~d}$ at room temperature, and the solvent was removed under reduced pressure to give a syrup $(307 \mathrm{~g})$. The $\mathrm{MeOH}$ extract was partitioned between hexane $(2900 \mathrm{ml})$ and aqueous $\mathrm{MeOH}\left[\mathrm{MeOH}(2500 \mathrm{ml})\right.$ and $\left.\mathrm{H}_{2} \mathrm{O}(100 \mathrm{ml})\right]$. Each layer was dried under reduced pressure to furnish the hexane-soluble fraction $(26.5 \mathrm{~g})$ and aqueous $\mathrm{MeOH}$-soluble fraction $(280.0 \mathrm{~g})$. The hexane-soluble fraction was successively subjected to silica gel column chromatography [hexane-acetone $(20: 1,5: 1,3: 1,2: 1,1: 1,0: 1)]$ and Diaion HP20 column chromatography $(80 \% \mathrm{MeOH}, 90 \% \mathrm{MeOH}, \mathrm{MeOH}$, acetone) to give fr. 1 (286 mg). Fraction 1 was recrystallized from hexane-acetone to afford $\mathbf{1 6}(22 \mathrm{mg})$. A part $(52.3 \mathrm{~g})$ of the aqueous $\mathrm{MeOH}$-soluble fraction was chromatographed over Diaion $\mathrm{HP} 20(30 \% \mathrm{MeOH}, 60 \% \mathrm{MeOH}, 90 \% \mathrm{MeOH}, \mathrm{MeOH}$, acetone) to give fr. 2-6. Chromatography of fr. $3(11.7 \mathrm{~g})$ over silica gel $\left[\mathrm{CHCl}_{3}-\right.$ $\left.\mathrm{MeOH}-\mathrm{H}_{2} \mathrm{O}(14: 2: 0.1,10: 2: 0.1,8: 2: 0.2,7: 3: 0.5,6: 4: 1,0: 1: 0)\right]$ gave fr. 7 -19. Fraction $8(61 \mathrm{mg})$, fr. $10(213 \mathrm{mg})$, fr. $11(213 \mathrm{mg})$, fr. 13 $(128 \mathrm{mg})$, and fr. $14(202 \mathrm{mg})$ were each subjected to HPLC on COSMOSIL 5C18 AR-II (Nacalai Tesque, Inc., $250 \mathrm{~mm} \times 20 \mathrm{~mm}$ i.d., $40 \% \mathrm{MeOH}$ ) to afford $\mathbf{1 4}(15 \mathrm{mg})$ from fr. $8, \mathbf{6}(23 \mathrm{mg}), \mathbf{2}(40 \mathrm{mg})$, and $\mathbf{1 1}(26 \mathrm{mg})$ from fr. $10,1(20 \mathrm{mg})$ from fr. 11, $3(4 \mathrm{mg})$ from fr. 13, and $\mathbf{1 2}(11 \mathrm{mg}), \mathbf{1 3}(28 \mathrm{mg})$, and $9(17 \mathrm{mg})$ from fr. 14. A part $(413 \mathrm{mg})$ of fr. $15(4717 \mathrm{mg})$ was subjected to HPLC under the same conditions as for fr. 8 to afford $\mathbf{1 0}(221 \mathrm{mg})$. Fraction $5(2290 \mathrm{mg})$ was subjected to silica gel column chromatography $\left[\mathrm{CHCl}_{3}-\mathrm{MeOH}-\mathrm{H}_{2} \mathrm{O}(14: 2: 0.1,10: 2: 0.1,8: 2: 0.2,7: 3: 0.5,6: 4: 1\right.$, $0: 1: 0)$ ] to give $15(101 \mathrm{mg})$. A part $(225.0 \mathrm{~g})$ of the aqueous $\mathrm{MeOH}$-soluble fraction was subjected to Diaion HP20 column chromatography $(30 \%$ $\mathrm{MeOH}, 60 \% \mathrm{MeOH}$, acetone) to give fr. $20-22$. Chromatography of fr. 21 $(85.4 \mathrm{~g})$ over silica gel $\left[\mathrm{CHCl}_{3}-\mathrm{MeOH}-\mathrm{H}_{2} \mathrm{O}(14: 2: 0.1,10: 2: 0.1,8: 2\right.$ : $0.2,7: 3: 0.5)]$ gave fr. $23-26$. Fraction $24(7.00 \mathrm{~g})$ and fr. $25(7.73 \mathrm{~g})$ were each subjected to HPLC $(30 \% \mathrm{MeOH})$ under the similar conditions as fr. 8 to afford $8(165 \mathrm{mg})$ and $7(348 \mathrm{mg})$ from fr. 24 , and $\mathbf{4}(54 \mathrm{mg})$ and 5 (170 $\mathrm{mg}$ ) from fr. 25.

Verbenabraside A (1): An amorphous powder, $[\alpha]_{\mathrm{D}}^{13}-86.1^{\circ}(c=2.1$, $\mathrm{MeOH})$. Positive FAB-MS m/z: $525[\mathrm{M}+\mathrm{H}]^{+}, 547[\mathrm{M}+\mathrm{Na}]^{+}$. Negative FAB-MS $m / z: 523[\mathrm{M}-\mathrm{H}]^{-}$. HR negative FAB-MS $m / z: 523.1937$ (Calcd for $\mathrm{C}_{25} \mathrm{H}_{31} \mathrm{O}_{12}:$ 523.1815). ${ }^{1} \mathrm{H}-\mathrm{NMR}$ spectral data: see Table $1 .{ }^{13} \mathrm{C}-\mathrm{NMR}$ spectral data: see Table 2 .

Verbenabraside B (2): An amorphous powder. $[\alpha]_{\mathrm{D}}^{13}-39.0^{\circ}(c=4.4$, $\mathrm{MeOH})$. Positive FAB-MS $m / z: 547[\mathrm{M}+\mathrm{Na}]^{+}$. Negative FAB-MS $m / z: 523$ $[\mathrm{M}-\mathrm{H}]^{-}$. HR negative FAB-MS $m / z$ : 523.1859 (Calcd for $\mathrm{C}_{25} \mathrm{H}_{31} \mathrm{O}_{12}$ : 523.1815). ${ }^{1} \mathrm{H}-\mathrm{NMR}$ spectral data: see Table $1 .{ }^{13} \mathrm{C}$-NMR spectral data: see Table 2.

Acidic Hydrolysis of 1 and 2 Compounds $1(2 \mathrm{mg})$ and $\mathbf{2}(2 \mathrm{mg})$ in $2 \mathrm{~N}$ $\mathrm{HCl}(1 \mathrm{ml})$ were each heated at $95^{\circ} \mathrm{C}$ for $1 \mathrm{~h}$. The reaction mixture was neutralized with $4 \mathrm{~N} \mathrm{NaOH}$ and then evaporated under reduced pressure to give a residue. The residue was extracted with $\mathrm{MeOH}$, and the $\mathrm{MeOH}$ extract was analyzed by HPLC under the following conditions: column, YMC pack
Polyamine II (YMC Co., Ltd., $4.6 \mathrm{~mm}$ i.d. $\times 250 \mathrm{~mm}$ ); solvent, $80 \% \mathrm{CH}_{3} \mathrm{CN}$; flow rate, $1.0 \mathrm{ml} / \mathrm{min}$; column temperature, $35^{\circ} \mathrm{C}$; detector, JASCO OR2090 plus; pump, JASCO PU-2080; and column oven, JASCO CO-2060. The retention time and optical activity of each of the samples were identical to those $\left[t_{\mathrm{R}}(\mathrm{min}), 13.7\right.$; optical activity, positive $]$ of D-glucose.

Assay of Scavenging Effect on DPPH The method of Uchiyama et $a l .{ }^{17)}$ was applied in a slightly modified manner. The EtOH solution $(1.00 \mathrm{ml})$ of each testing sample was added to a mixture of $0.1 \mathrm{M}$ acetic acid buffer $(\mathrm{pH} 5.5,1.00 \mathrm{ml})$ and $0.5 \mathrm{~mm}$ DPPH EtOH solution $(0.50 \mathrm{ml})$ in a test tube and left to stand at room temperature for $30 \mathrm{~min}$. The absorbance of the resulting solution was measured at $517 \mathrm{~nm}$. $\alpha$-Tocopherol and L-cysteine were used as standard samples.

Acknowledgments We express our appreciation to Mr. K. Takeda and Mr. T. Iriguchi of Kumamoto University for their measurement of the NMR and MS spectra.

\section{References}

1) Milz S., Rimpler H., Z. Naturfolisch., 34c, 319-329 (1979).

2) Franke A., Rimpler H., Phytochemistry, 26, 3015-3020 (1987).

3) Jensen S. R., Kirk O., Nielsen B. J., Norrestam R., Phytochemistry, 26, 1725-1731 (1987).

4) Jensen S. R., Nielsen B. J., Phytochemistry, 19, 2685-2688 (1980).

5) Damtoft S., Jensen S. R., Nielsen B. J., Phytochemistry, 20, 27172732 (1981).

6) Nishimura H., Sasaki H., Morota T., Chin M., Mitsuhashi H., Phytochemistry, 29, 3303-3306 (1990).

7) Ono M., Morinaga H., Masuoka C., Ikeda T., Okawa M., Kinjo J., Nohara T., Chem. Pharm. Bull., 53, 1175-1177 (2005).

8) Sasaki H., Nishimura H., Chin M., Mitsuhashi H., Phytochemistry, 28, 875-879 (1989).

9) Kanchanapoom T., Kamel M. S., Kasai R., Yamasaki K., Picheansoonthon C., Hiraga Y., Phytochemistry, 56, 369-372 (2001).

10) Achenbach H., Löwel M., Waibel R., Gupta M., Solis P., Planta Med., 58, 270-272 (1992).

11) Ushiyama M., Furuya T., Phytochemistry, 28, 3009-3013 (1989).

12) Ono M., Koto M., Komatsu H., Igoshi K., Kobayashi H., Ito Y., Nohara T., Food Sci. Technol. Res., 10, 56-59 (2004).

13) Li Y., Satake M., Oshima Y., Ohizumi Y., Chem. Lett., 32, 728-729 (2003).

14) Kasai R., Okihara M., Asakawa J., Tanaka O., Tetrahedron Lett., 1977, 175-178 (1977).

15) Seo S., Tomita Y., Tori K., Yoshimura Y., J. Am. Chem. Soc., 100, $3331-3339$ (1978).

16) Ono M., Yamamoto M., Yanaka T., Ito Y., Nohara T., Chem. Pharm. Bull., 49, 82-86 (2001).

17) Uchiyama M., Suzuki Y., Fukuzawa K., Yakugaku Zasshi, 88, 678683 (1968). 